\title{
NUMERICAL ANALYSIS OF A MECHANICAL WAVE DAMPING IN THE RUBBER-CONCRETE COMPOSITE USING THE ADINA SOFTWARE
}

This paper presents numerical analysis concerning a rubber-concrete composite which can be considered as a structural element designed to form walls. Structural elements that carry the compressive load have a rubber with a specific shape embedded during the technological process. Therefore, the prefabricated block offers an additional damping property of a mechanical wave resulting from the dynamic load. The numerical analysis using the ADINA software revealed significant mechanical wave damping in the composite analysed in the study for different types of dynamic load.

Keywords: Composites, Mooney-Rivlin, non-linear hyperelastic material, damping, ADINA.

\section{Introduction}

Nowadays, due to specific mechanical properties, composite materials are frequently used in civil engineering to build various types of structures. There are a number of composites manufactured today, whereas the most popular solution is to combine concrete with steel. It should be noted that, depending on the type of structure, at least few different composites can be used. For example, glued laminated timber can be considered to be used in wooden structures. Materials such as concretesteel composites combine advantages of these two different materials, which results in a more efficient transfer of tensile and compressive stresses in the structure. Moreover, combination of rubber and other materials such as steel are also desirable from the engineering point of view. These compounds are used mainly in bridge construction as bearings and the use of rubber allows for reduction in vibration from dynamic load i.e. moving vehicles, pedestrians etc. However, there are various types of composites and the research on concrete-rubber materials remains to be at the initial stage.

Nowadays, expensive experimental tests are more frequently replaced with the numerical analysis based on the finite element method due to its reduced time consumption and lower costs. FEM software does not only help compute structural displacements and internal stresses. It is also possible to analyse mechanical wave propagation.
It is assumed that the first researchers to start experimental tests on rubber in order to describe its behaviour were Mooney and Rivlin [1 and 2]. In the forties and the fifties of the 20th century, they developed a mathematical model describing the rubber behaviour caused by external load. In the following years, their research was continued by Zahorski [ 3 and 4], who modified the Mooney-Rivlin mathematical model to describe rubber behaviour for higher external loads. It is assumed that MooneyRivlin model can be safely applied to rubber materials where the value of strain equals 1.4, whereas for Zahorski this value equals 3 . The study of shock wave phenomena in selected rubber materials was presented in [5], where the evolution and reflection of particular waves is considered. Experimental tests of mechanical wave propagation in layered composite materials were also the focus of the study by Kosiński [6]. Due to rapid technological advances many research centres at the end of the 20th century were already equipped with computers and finite element method based software, which resulted in many publications concerning the FEM method used in different fields of science (see [7]). A great number of papers have used FEM to examine mechanical wave propagation in different materials. One example is modelling of wave propagation with a hyperelastic Mooney-Rivlin and Zahorski material model presented in [8 and 9], based on the ADINA software using the finite element method.

This paper presents a numerical analysis of damping of mechanical wave propagation caused by different types of dynamic

\footnotetext{
* ${ }^{1}$ Izabela Major, ${ }^{1}$ Maciej Major, ${ }^{2}$ Daniela Kucharova

${ }^{1}$ Faculty of Civil Engineering, Czestochowa University of Technology, Poland

${ }^{2}$ Faculty of Civil Engineering, University of Zilina, Slovakia

E-mail: imajor@bud.pcz.czest.pl
} 
load in a composite made of concrete with rubber pads compared to the solid concrete block. Four different types of dynamical load were studied: concentrated force, vertical line load, horizontal line load and pressure on the frontal surface of the block, respectively. The ADINA software which is fully based on the finite element method was chosen to perform numerical analysis.

\section{Hyperelastic Mooney-Rivlin material}

The constitutive equations describe the behaviour of the specified material medium under the influence of various types of external factors.

The constitutive relation for the hyperelastic Mooney-Rivlin material can be written as:

$W\left(I_{1}, I_{2}\right)=C_{1}\left(I_{1}-3\right)+C_{2}\left(I_{2}-3\right)$

where: $C_{p}, C_{2}$ are the material constants, whereas $I_{p}, I_{2}$ are invariants of deformation tensor. According to the above equation, one can be stated that the elastic energy for the discussed incompressible isotropic hyperelastic Mooney-Rivlin material is linearly dependent on invariants of deformation tensor.

Table 1 presents elastic constants for rubber analysed in this study. The values are based on the study [3] and were obtained by computing into the SI system.

Constants $\mathrm{C}_{1}, \mathrm{C}_{2}$

Table 1

\begin{tabular}{|c|c|c|}
\hline Constants & $\mathrm{C}_{1}[\mathrm{~Pa}]$ & $\mathrm{C}_{2}[\mathrm{~Pa}]$ \\
\hline Value & $6.278 \cdot 10^{4}$ & $8.829 \cdot 10^{3}$ \\
\hline
\end{tabular}

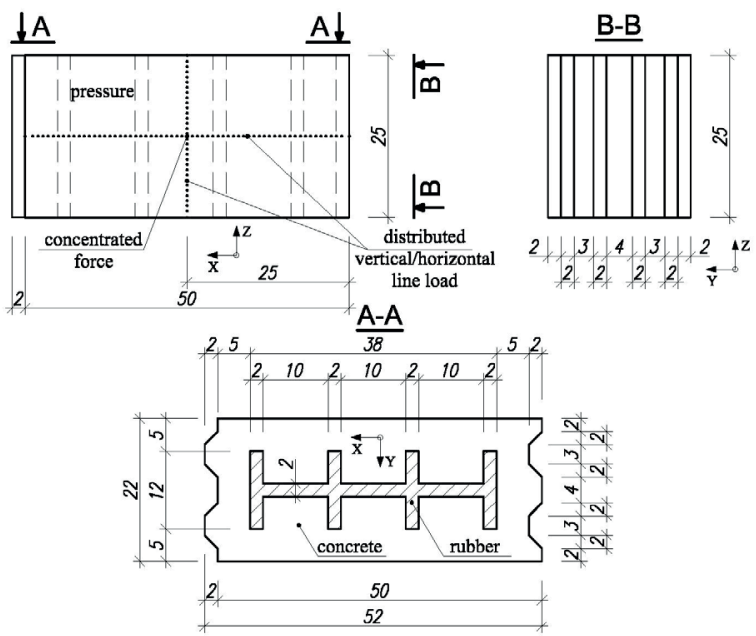

Fig. 1 Scheme of the analysed concrete-rubber block

as mechanical wave propagation. In the following stages of the analysis, the effective stress values resulting from the pulse load were read in the measurement points 1 to 4 (see Fig. 2) and $1 R-4 R$ which were the reflection of points 1 to 4 located on the rear side of the block. The effective stress was read as a mean value from the adjacent elements to the black dots denoting the measurement points presented in Fig. 2 .

The following boundary conditions were used in the model with respect to the Cartesian coordinate system presented in Fig. 1: bottom surface of the block located on the XY plane was fixed in the direction of $Z$ axis, whereas side surfaces of the block located on the $\mathrm{YZ}$ plane were fixed both in the $\mathrm{X}$ and $\mathrm{Y}$ axis direction.

Discretization of the block model was obtained using 3D-Solid finite elements (tetrahedrons), with the size of each

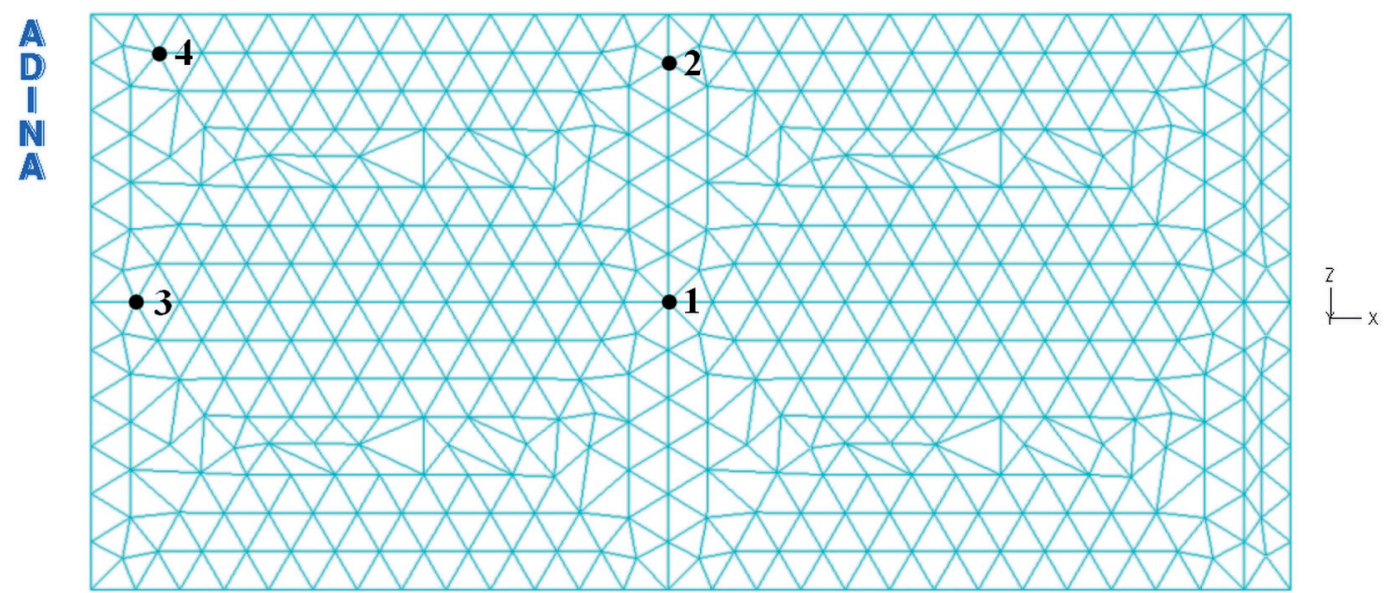

Fig. 2 Discrete model of the analysed concrete-rubber block and effective stress measurement points 1-4; Points $1 R-4 R$ are the reflection of points 1-4 located on the rear surface of the block 
were adopted for reading of the effective stress: $t_{1}=1 \times 10^{-5} \mathrm{~s}$ and $\mathrm{t}_{2}=6 \times 10^{-5} \mathrm{~s}$. Furthermore, the disturbance propagation resulting from the different types of dynamic load in the composite and solid concrete block was presented in Figs. 3-6.
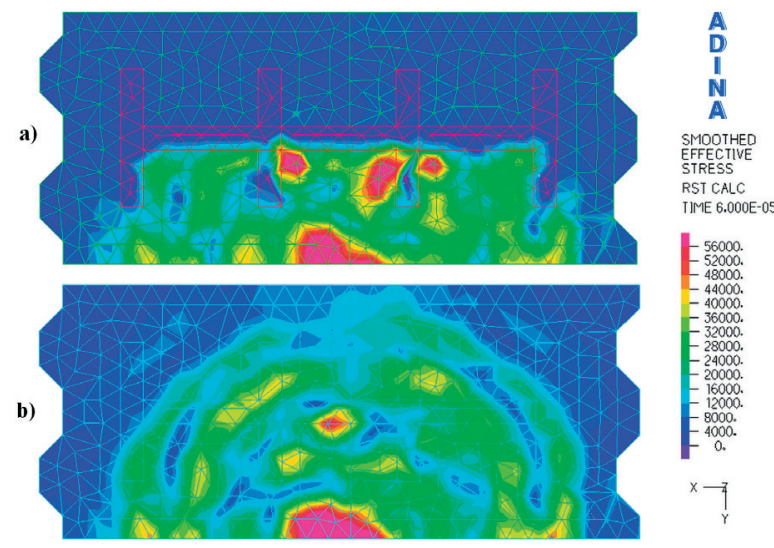

Fig. 3 Effective stress at $t=0.00006 \mathrm{~s}$,

(a) composite blocks made of concrete and rubber,

(b) solid concrete block (a dynamic concentrated force load)

Comparison of the effective stress redistribution on the top surface of the block shown in Fig. 3-6 reveals that perpendicular mechanical wave propagation in the composite (see Figs. 3a-6a) at time $\mathrm{t}=6 \times 10^{-5} \mathrm{~s}$ is significantly reduced behind the rubber pads, whereas in the solid concrete block (see Fig. 3b-6b), the wave is only slightly damped with material properties. It is noticeable that the effective stress on the rear block side in the composite ranges from 4 to $8 \mathrm{kPa}$, while in the concrete block, stresses fit the range of $4-36 \mathrm{kPa}$.
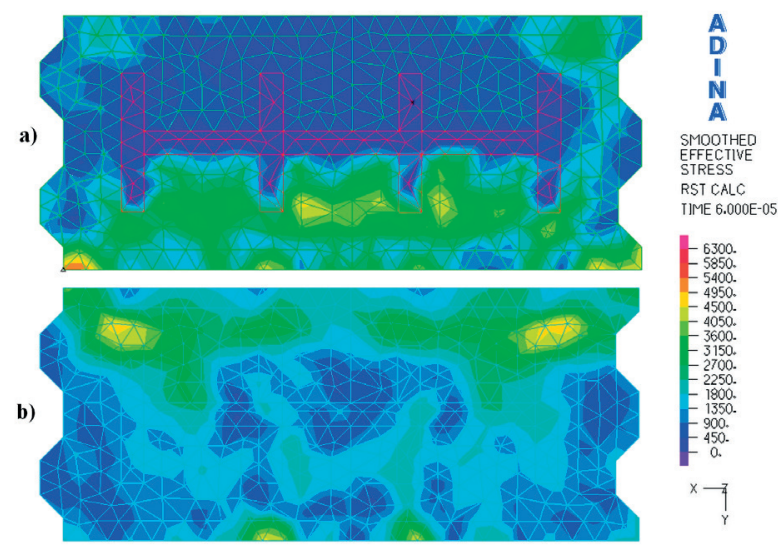

Fig. 4 Effective stress at $t=0.00006 \mathrm{~s}$,

(a) composite blocks made of concrete and rubber,

(b) solid concrete block (a dynamic pressure load)
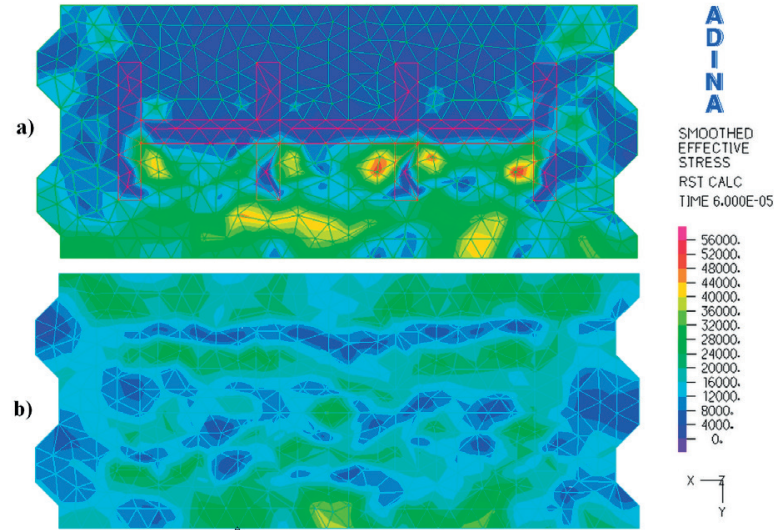

Fig. 5 Effective stress at $t=0.00006 \mathrm{~s}$,

(a) composite blocks made of concrete and rubber,

(b) solid concrete block (a dynamic horizontal line load)

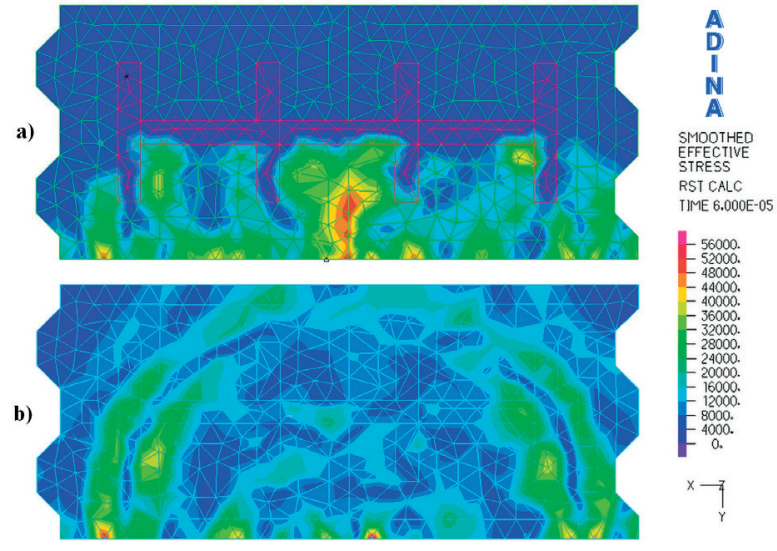

Fig. 6 Effective stress at $t=0.00006 \mathrm{~s}$,

(a) composite blocks made of concrete and rubber,

(b) solid concrete block (a dynamic vertical line load)

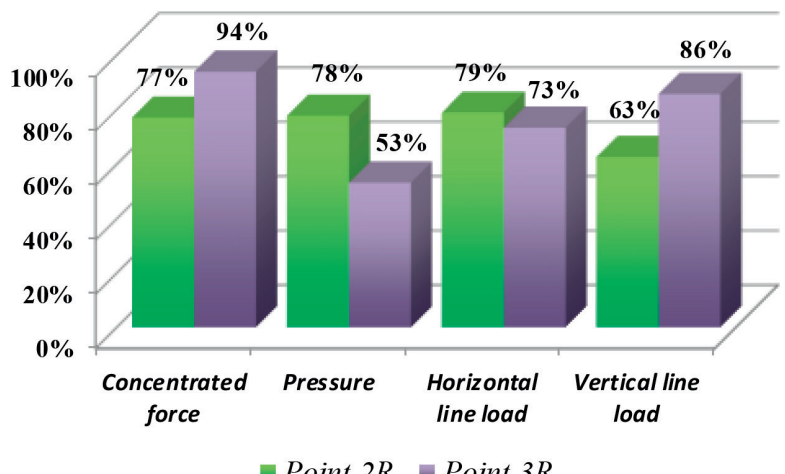

- Point $2 R=$ Point $3 R$

Fig. 7 Mechanical wave percentage damping on the outer surface ("XZ" plane) of the composite block in relation to the solid concrete block at the $2 R$ and $3 R$ measurement points for a different dynamic loads applied; Time $t=6 \times 10^{5} \mathrm{~s}$ 
Comparison of the effective stress in selected measurement points in the composite and solid concrete block for different types of dynamical load and two different time values $\mathrm{t}_{1}=1 \times 10^{-5} \mathrm{~s}$ and $\mathrm{t}_{2}=6 \times 10^{-5} \mathrm{~s}$

Table 2

\begin{tabular}{|c|c|c|c|c|c|c|c|c|c|}
\hline \multicolumn{5}{|c|}{ Concentrated force } & \multicolumn{5}{|c|}{ Pressure load } \\
\hline \multicolumn{5}{|c|}{ Effective stress [Pa] } & \multicolumn{5}{|c|}{ Effective stress [Pa] } \\
\hline \multirow{2}{*}{ 䓂 } & \multicolumn{2}{|c|}{ Composite } & \multicolumn{2}{|c|}{ Solid concrete block } & \multirow{2}{*}{ e⿳亠二口犬 } & \multicolumn{2}{|c|}{ Composite } & \multicolumn{2}{|c|}{ Solid concrete block } \\
\hline & $t_{1}$ & $t_{2}$ & $t_{1}$ & $t_{2}$ & & $t_{1}$ & $t_{2}$ & $t_{1}$ & $t_{2}$ \\
\hline 1 & $1.50 \mathrm{E}+06$ & $1.75 \mathrm{E}+05$ & $1.50 \mathrm{E}+06$ & $1.78 \mathrm{E}+05$ & 1 & $5.73 \mathrm{E}+03$ & $4.11 \mathrm{E}+03$ & $5.72 \mathrm{E}+03$ & $2.37 \mathrm{E}+03$ \\
\hline 1R & $8.59 \mathrm{E}-02$ & $4.79 \mathrm{E}+03$ & $2.43 \mathrm{E}+00$ & $1.09 \mathrm{E}+04$ & 1R & $1.24 \mathrm{E}-01$ & $2.82 \mathrm{E}+03$ & $2.41 \mathrm{E}-01$ & $2.45 \mathrm{E}+03$ \\
\hline 2 & $5.54 \mathrm{E}+02$ & $5.88 \mathrm{E}+04$ & $5.51 \mathrm{E}+02$ & $5.75 \mathrm{E}+04$ & 2 & $5.88 \mathrm{E}+03$ & $3.15 \mathrm{E}+03$ & $5.87 \mathrm{E}+03$ & $2.03 \mathrm{E}+03$ \\
\hline $2 \mathrm{R}$ & 7.32E-02 & $2.34 \mathrm{E}+03$ & 3.93E-01 & $1.02 \mathrm{E}+04$ & $2 \mathrm{R}$ & $3.54 \mathrm{E}-02$ & $4.67 \mathrm{E}+02$ & $3.24 \mathrm{E}-01$ & $2.10 \mathrm{E}+03$ \\
\hline 3 & $5.90 \mathrm{E}-01$ & $2.40 \mathrm{E}+04$ & $5.56 \mathrm{E}-01$ & $2.47 \mathrm{E}+04$ & 3 & $6.45 \mathrm{E}+03$ & $4.86 \mathrm{E}+03$ & $6.44 \mathrm{E}+03$ & $2.51 \mathrm{E}+03$ \\
\hline $3 \mathbf{R}$ & 7.90E-04 & $5.89 \mathrm{E}+01$ & 4.95E-02 & $9.80 \mathrm{E}+02$ & $3 R$ & $2.45 \mathrm{E}-01$ & $1.34 \mathrm{E}+03$ & 4.40E-01 & $2.86 \mathrm{E}+03$ \\
\hline 4 & $2.18 \mathrm{E}-01$ & $9.19 \mathrm{E}+03$ & $2.22 \mathrm{E}-01$ & $8.75 \mathrm{E}+03$ & 4 & $5.50 \mathrm{E}+03$ & $559 \mathrm{E}+03$ & $5.49 \mathrm{E}+03$ & $2.30 \mathrm{E}+03$ \\
\hline $4 R$ & 7.71E-04 & $9.13 \mathrm{E}+01$ & $2.29 \mathrm{E}-02$ & $5.25 \mathrm{E}+02$ & $4 \mathrm{R}$ & $2.74 \mathrm{E}-01$ & $1.95 \mathrm{E}+03$ & 4.35E-01 & $2.85 \mathrm{E}+03$ \\
\hline
\end{tabular}

\begin{tabular}{|c|c|c|c|c|c|c|c|c|c|}
\hline \multicolumn{5}{|c|}{ Horizontal line load } & \multicolumn{5}{|c|}{ Vertical line load } \\
\hline \multicolumn{5}{|c|}{ Effective stress [Pa] } & \multicolumn{5}{|c|}{ Effective stress [Pa] } \\
\hline \multirow{2}{*}{ 䓂 } & \multicolumn{2}{|c|}{ Composite } & \multicolumn{2}{|c|}{ Solid concrete block } & \multirow{2}{*}{ : } & \multicolumn{2}{|c|}{ Composite } & \multicolumn{2}{|c|}{ Solid concrete block } \\
\hline & $t_{1}$ & $t_{2}$ & $t_{1}$ & $t_{2}$ & & $t_{1}$ & $t_{2}$ & $t_{1}$ & $t_{2}$ \\
\hline 1 & $3.86 \mathrm{E}+05$ & $1.06 \mathrm{E}+05$ & $3.86 \mathrm{E}+05$ & $9.29 \mathrm{E}+04$ & 1 & $3.86 \mathrm{E}+05$ & $6.73 E+04$ & $3.86 \mathrm{E}+05$ & $6.66 \mathrm{E}+04$ \\
\hline 1R & $2.17 \mathrm{E}-01$ & $5.14 \mathrm{E}+03$ & $3.58 \mathrm{E}+00$ & $1.27 \mathrm{E}+04$ & 1R & $8.49 \mathrm{E}-01$ & $1.89 \mathrm{E}+04$ & $1.90 \mathrm{E}+00$ & $1.11 \mathrm{E}+04$ \\
\hline 2 & $5.04 \mathrm{E}+02$ & $3.34 \mathrm{E}+04$ & $4.96 \mathrm{E}+02$ & $3.28 \mathrm{E}+04$ & 2 & $4.40 \mathrm{E}+05$ & $7.69 \mathrm{E}+04$ & $4.40 \mathrm{E}+05$ & $7.25 \mathrm{E}+04$ \\
\hline $2 \mathrm{R}$ & $1.19 \mathrm{E}-01$ & $3.53 \mathrm{E}+03$ & $8.25 \mathrm{E}-01$ & $1.67 \mathrm{E}+04$ & $2 \mathrm{R}$ & $2.60 \mathrm{E}-01$ & $3.85 \mathrm{E}+03$ & $2.20 \mathrm{E}+00$ & $1.03 \mathrm{E}+04$ \\
\hline 3 & $4.62 \mathrm{E}+05$ & $4.98 \mathrm{E}+04$ & $4.62 \mathrm{E}+05$ & $4.99 \mathrm{E}+04$ & 3 & $8.67 \mathrm{E}-01$ & $2.79 \mathrm{E}+04$ & $8.50 \mathrm{E}-01$ & $2.97 \mathrm{E}+04$ \\
\hline $3 R$ & $1.85 \mathrm{E}+00$ & $3.78 \mathrm{E}+03$ & $3.29 \mathrm{E}+00$ & $1.42 \mathrm{E}+04$ & $3 R$ & $1.07 \mathrm{E}-02$ & $2.26 \mathrm{E}+02$ & $8.74 \mathrm{E}-02$ & $1.59 \mathrm{E}+03$ \\
\hline 4 & $2.82 \mathrm{E}+02$ & $2.32 \mathrm{E}+04$ & $2.78 \mathrm{E}+02$ & $1.73 \mathrm{E}+04$ & 4 & $1.23 \mathrm{E}+00$ & $3.55 \mathrm{E}+04$ & $1.15 \mathrm{E}+00$ & $3.92 \mathrm{E}+04$ \\
\hline $4 \mathrm{R}$ & $5.22 \mathrm{E}-01$ & $1.39 \mathrm{E}+04$ & 9.03E-01 & $1.91 \mathrm{E}+04$ & $4 \mathrm{R}$ & $1.54 \mathrm{E}-03$ & $1.16 \mathrm{E}+02$ & $8.71 \mathrm{E}-02$ & $1.54 \mathrm{E}+03$ \\
\hline
\end{tabular}

The values presented in Table 2 show that the effective stress on the frontal $\mathrm{XZ}$ plane of the block is slightly higher for the composite compared to the solid concrete. This is due to lower amount of concrete material in the block and its higher stiffness compared to rubber, which results in higher force distribution in this material. It should also be noted that at the time $\mathrm{t}=6 \times 10^{-5}$ $\mathrm{s}$ there were both higher and lower values of effective stress on the frontal block surface, caused by the mechanical wave interference and refraction of the reflected wave in the rubber material. Figure 7 shows damping of mechanical wave propagation in the composite block made of concrete and rubber pads for different types of dynamical load in the measurement points $2 \mathrm{R}$ and $3 \mathrm{R}$ at $\mathrm{t}=6 \times 10^{-5} \mathrm{~s}$ compared to the solid concrete block.

Based on the results presented in Fig. 7, it can be found that damping in the composite material fits the range of $53-94 \%$ for different types of dynamical load applied to the frontal surface of the block. The highest damping was observed for the concentrated force, because the mechanical wave had to propagate through the rubber material for both $2 \mathrm{R}$ and $3 \mathrm{R}$ points.

Damping for the above force is higher at the $3 R$ point because the rubber pads were not only inserted in the $\mathrm{XZ}$ plane of the block, but they were also located in the $\mathrm{YZ}$ plane, providing additional damping in the longitudinal direction of the block. With the pressure and horizontal-line dynamical load shown in Fig. 7, it is noticeable that damping at point $3 \mathrm{R}$ is relatively smaller for the point $2 \mathrm{R}$. This phenomenon was connected with the location of the point $3 \mathrm{R}$ : mechanical wave propagation from both pressure and horizontal line load propagated through the solid concrete material near side surface located on the YZ plane. It is remarkable that with longer distances from the applied 


\section{COMMNICOIIONS}

dynamic load to the measurement point and more rubber inserts present in the way of disturbance propagation, the disturbance could be efficiently diminished on the outer side of the block.

\section{Conclusion}

This paper presents the reduction in disturbance wave propagation in the composite block made of concrete and rubber. It was found that despite the type of the dynamic load to the frontal surface of the composite block, the disturbance wave propagation on the outer block side was significantly reduced from $53 \%$ up to $94 \%$ compared to the solid concrete block. Therefore, composite blocks could be used in wall structures to transfer compressive forces as well as to provide a barrier from the external sources of vibrations.
The main advantages of the innovative composite solution include: low cost of implementation in the technological process, where special mould would have to be embedded in the beginning of the process and, after the mould removal, rubber pads could be either inserted or injected. The blocks are symmetrical in the horizontal plane to prevent from incorrect assembly of the block. Another advantage is also that the materials are recyclable. The main drawback is a small reduction in load bearing capacity of each block. The bigger the rubber pads, the more significant reduction in load bearing capacity, whereas optimal dimensions of inserts and concrete blocks could be easily determined via numerical analysis. It should be noted that the configuration of rubber pads and its dimensions presented in the paper are only the examples of possible patterns. Therefore, they can be considered as the basis for further modifications and experimental tests of these construction materials.

\section{References}

[1] MOONEY, M.: A Theory of Large Deformations. J. Appl. Phys., 11, 1940.

[2] RIVLIN, R. S., SAUNDERS, D. W.: Large Elastic Deformations of Isotropic Materials, VII Experiments of the deformation of rubber, Phil. Trans. Roy. Soc. Lond. 243, 1951, 251-288

[3] ZAHORSKI, S.: Experimental Study of some Mechanical Properties of Rubber (in Polish), Rozprawy inzynierskie, vol. 10 (1), 1962.

[4] ZAHORSKI, S.: A Form of Elastic Potential for Rubber-Like Materials. Arch. of Mechanics, 5, 1959.

[5] KOSINSKI, S.: Reflection and Evolution of the Shock Wave in the Selected Hyperelastic Materials (in Polish), Wydawnictwo IPPT PAN: Warszawa, 1995, ISSN 0208-5658.

[6] KOSINSKI, S.: Elastic Waves in the Rubber-Like Layered Composites (in Polish), Wydawnictwo Politechniki Lodzkiej : Lodz, 2007. ISBN 978-83-7283-220-7. 116p.

[7] MELCER, J.: A Vehicle Bridge Interaction, Communications - Scientific Letters of the University of Zilina, 2007, 3/2007, 5-10.

[8] MAJOR, I., MAJOR, M.: Comparative Analysis of the Distribution of Effective Stress in Mooney and Zahorski Materials using Adina Software, Advanced Material Research, 2014, 1020, 165-170.

[9] MAJOR, I., MAJOR, M.: Travelling Waves in a thin Layer Composed of Nonlinear Hyperelastic Zahorski Material, J. of Theoretical and Applied Mechanics, 2009, 47, 1, 109-126. 